\title{
Alteration of the proteome profile of the pancreas in diabetic rats induced by streptozotocin
}

\author{
YONG-LIANG JIANG，YOU NING，XIAO-LEI MA，YAN-YAN LIU，YU WANG，ZENG ZHANG, \\ CHUN-XIAO SHAN, YU-DONG XU, LEI-MIAO YIN and YONG-QING YANG
}

Yue Yang Hospital, Shanghai University of Traditional Chinese Medicine, Shanghai 200030, P.R. China

Received February 18, 2011; Accepted April 12, 2011

DOI: $10.3892 / \mathrm{ijmm} .2011 .696$

\begin{abstract}
Type 1 diabetes mellitus (T1DM) is receiving increased attention. To obtain a better understanding of the mechanism underlying T1DM, we performed a proteomic study on a rat model induced by streptozotocin. Pancreatic proteins were separated by two-dimensional gel electrophoresis. Eighteen protein spots were differentially expressed $(\mathrm{P}<0.05)$ with 2 -fold or more increased or decreased intensity in the diabetic rats as compared with controls, of which 11 protein spots were up-regulated and 7 protein spots were downregulated. These protein spots were successfully identified by liquid chromatography-electrospray ionization tandem mass spectrometry. The $60 \mathrm{kDa}$ heat shock protein, the carbonyl reductase 1 (Cbr1), the hydroxyacyl-CoA dehydrogenase, $\Delta^{3,5}, \Delta^{2,4}$-dienoyl-CoA isomerase, the elongation factor $1-\delta$, the $26 \mathrm{~S}$ protease regulatory subunit 7 and the transitional endoplasmic reticulum ATPase were up-regulated, while the $78 \mathrm{kDa}$ glucose-regulated protein, peroxiredoxin 4 and plakoglobin were down-regulated. The expression change of Cbrl which is closely related to diabetic complications was further validated by Western blotting. Our results and those of the bioinformatics analysis suggest that oxidative stress, the Wnt pathway, fatty acid degradation and glucose transport may be closely related to T1DM.
\end{abstract}

Correspondence to: Professor Yong-Qing Yang, Yue Yang Hospital, Shanghai University of Traditional Chinese Medicine, 650 South Wanping Road, Shanghai 200030, P.R. China

E-mail: yyq@shutcm.edu.cn

Abbreviations: T1MD, type 1 diabetes mellitus; NOD, non-obese diabetic; STZ, streptozotocin; SD, Sprague-Dawley; IEF, isoelectric focusing; 2-DE, two-dimensional gel electrophoresis; LC-ESI-MS/ MS, liquid chromatography-electrospray ionization tandem mass spectrometry; PPI, protein-protein interaction; Cbr1, carbonyl reductase 1; HSP60, $60 \mathrm{kDa}$ heat shock protein; GRP78, $78 \mathrm{kDa}$ glucose-regulated protein; PRX4, peroxiredoxin 4; HCDH, hydroxyacyl-CoA dehydrogenase; TER, transitional endoplasmic reticulum

Key words: pancreas, proteomics, type 1 diabetes mellitus, streptozotocin, Sprague-Dawley rats

\section{Introduction}

Type 1 diabetes mellitus (T1DM) is a multifactorial disease, which is characterized by the destruction of the insulinsecreting $\beta$ cells of the islets of Langerhans in the pancreas. The destruction of $\beta$ cells leads to severe insulin depletion, which results in hyperglycemia, because of hepatic overproduction of glucose by glycogenolysis and gluconeogenesis and decreased cellular uptake of glucose from the circulation. The onset of T1DM is involved in different genetic and/or environmental susceptibility determinants, with different mechanisms leading to $\beta$ cell destruction (1). Increased oxidative stress has been reported to be a participant in the onset of diabetes $(2,3)$, which can cause heavy damage to $\beta$ cells because of very low amounts of intrinsic antioxidant enzymes in $\beta$ cells (4). It has also been reported that the autoimmune attack is involved in $\beta$ cell destruction of T1DM (5). However, the exact mechanisms of this disease still remain largely unknown.

Animal models are widely used to study the underlying mechanisms and consequences of diabetes (6). Animal models for T1DM include genetic models and chemical-induced models. The genetic models include the non-obese diabetic (NOD) mouse and the Bio-Breeding Wistar rat. The models of diabetes with the genetic defects may not be ideal for the study of the disease in humans, because these gene mutations are rare in the general population (7). The commonly used chemical-induced models in the mouse and the rat for assessing the mechanism of T1DM, screening potential therapies for this condition, and evaluating therapeutic options are the streptozotocin (STZ)-induced models (8). The diabetogenic property of STZ is characterized by the selective destruction of $\beta$ cells of pancreatic islets, causing insulin deficiency, hyperglycemia, polydipsia and polyuria, all of which mimic human T1DM (9), thus making this model better fitted for the study of T1DM.

Proteomics is a powerful tool to describe changes in protein expression and modification, and holds the promise of providing major contributions to diabetes research (6). Sanchez et al built the first reference database of the mouse islet proteome (10). Xie et al performed proteomic analysis of mouse islets after multiple low-dose STZ injections, and found 4 proteins that were up-regulated and 3 that were down-regulated in diabetic mice (11). In a series of experiments, researchers examined the effect of IL- $1 \beta$ on the proteome profile of rat 
islets of Langerhans from Wistar Furth rats $(12,13)$ and later in Bio Breeding diabetes-prone rats $(14,15)$. They found that differentially expressed proteins from both rat strains were involved in many pathways, such as energy transduction, redox potentials, glycolysis and the Krebs cycle (15). Yang et al carried out proteomic analysis of remnants of the pancreas after $90 \%$ pancreatectomy, and determined that differentially expressed proteins in regenerating rat pancreas were involved in cell growth, lipid and energy metabolism, protein and amino acid metabolism and signal transduction (16). Due to its potential to dissect complex human disorders, proteomics analysis may be used to add insight into diabetes research (6).

In the present study, we carried out proteomic analysis of the pancreas of diabetic Sprague-Dawley (SD) rats induced by STZ. The proteome profile of the pancreas was assessed by two-dimensional gel electrophoresis (2-DE) followed by mass spectrometry analysis (MS) to identify differentially expressed proteins and bioinformatics analysis with the purpose of providing insight into the mechanism of T1DM.

\section{Materials and methods}

Animals and diabetes induction. Experiments were conducted in 6-week-old male SD rats (210-230 g; SLAC Laboratory Animal Centre, Shanghai, China). Rats were housed in a temperature controlled room $\left(22 \pm 1^{\circ} \mathrm{C}\right)$ under a 12:12 h lightdark cycle, with standard rodent chow and water ad libitum. The experiments were conducted in accordance with the regulations of the State Science and Technology Commission for the care and use of laboratory animals (State Science and Technology Commission Order no. 2, 1988). Rats were randomly divided into two groups $(n=8)$, the control group and the diabetes group. Diabetes was induced following overnight fasting by a single intraperitoneal injection of STZ $(60 \mathrm{mg} / \mathrm{kg}$; Sigma-Aldrich, St. Louis, MO, USA) dissolved in citric acidtrisodium citrate buffer (0.1 M, pH 4.5; Shanghai Chemical Reagent Co., Shanghai, China). The induction of diabetes was considered successful when blood glucose exceeded $16.7 \mathrm{mmol} / \mathrm{l}$ $48 \mathrm{~h}$ after the STZ injection. The control rats received buffer alone. Blood glucose was measured using a compact glucometer (Accu-Check Advantage; Roche Diagnostics, Shanghai, China) on Days 0, 1, 2, 3, 5, 7, 9, 11, 13 and 15 .

Histology. Pancreases were immediately removed after rats were sacrificed, and then rinsed in ice-cold saline. Pancreas samples for histology were fixed in $10 \%$ neutral buffered formalin $(\mathrm{v} / \mathrm{v})$, dehydrated in a graded series of ethanol, and then embedded in paraffin. Following embedding, $5-\mu$ m-thick sections were cut, stained with haematoxylin and eosin, and observed using light microscopy (x400).

Preparation of pancreas samples. Pancreas samples for proteomics were pulverized in liquid nitrogen, resolved in solution 1 of the ReadyPrep sequential extraction kit (Bio-Rad Laboratories, Hercules, CA, USA) with the following additions: PMSF (1 mM), DNase $(20 \mu \mathrm{g} / \mathrm{ml})$, and RNase $(10 \mu \mathrm{g} / \mathrm{ml})$, sonicated on ice $(3 \times 5 \mathrm{sec})$, and then stored at $4^{\circ} \mathrm{C}$ for $1 \mathrm{~h}$. Samples were centrifuged at $14,000 \times \mathrm{g}$ for $30 \mathrm{~min}$ at $4^{\circ} \mathrm{C}$ and then the supernatants were collected. Protein concentrations were determined by the Bradford method (Bio-Rad Laboratories).
For 2-DE analysis, the protein extracts of each animal in the same group were equally pooled according to the protein concentration and stored at $-80^{\circ} \mathrm{C}$ until use.

2-DE. Three independent experiments of 2-DE were performed to ensure reproducibility for each group. 2-DE was carried out using a Bio-Rad 2-DE system following the Bio-Rad handbook. Briefly, a $100 \mu \mathrm{g}$ protein sample was applied for isoelectric focusing (IEF) using the ReadyStrip IPG strips (17 cm, nonlinear pH 3-10; Bio-Rad). The strips were placed into a Protean IEF cell (Bio-Rad) and were rehydrated at $50 \mathrm{~V}$ for $12 \mathrm{~h}$, and then the proteins were separated based on their pI according to the following protocol: $250 \mathrm{~V}$ with a linear climb for $30 \mathrm{~min}, 1,000 \mathrm{~V}$ with a rapid climb for $60 \mathrm{~min}$, $10,000 \mathrm{~V}$ with a linear climb for $5 \mathrm{~h}, 10,000 \mathrm{~V}$ with a rapid climb until $60,000 \mathrm{Vh}$ were reached, and $500 \mathrm{~V}$ with a rapid climb for $30 \mathrm{~min}$. After IEF, the IPG strips were equilibrated

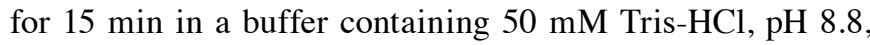
$30 \%$ glycerol, $7 \mathrm{M}$ urea, 2\% SDS and 2\% DTT followed by a further equilibration in a similar buffer (but containing $2.5 \%$ iodoacetamide instead of DTT) for $15 \mathrm{~min}$ and then placed on $13 \%$ homogeneous SDS-PAGE gels for electrophoresis using a Protean II xi Cell system (Bio-Rad) according to the following protocol: $10 \mathrm{~mA} / \mathrm{gel}$ for $30 \mathrm{~min}$ and $24 \mathrm{~mA} / \mathrm{gel}$ for $6 \mathrm{~h}$. After that, the gels were silver-stained.

Image analysis and liquid chromatography-electrospray ionization tandem mass spectrometry (LC-ESI-MS/MS). The silver-stained gels were scanned by a GS-800 densitometer (Bio-Rad) and then analyzed using the PDQuest software (Bio-Rad). The individual protein spot quantity was normalized as follows: the raw quantity of each spot in a member gel was divided by the total quantity of the valid spots in the gel, and normalized spot intensities were expressed in ppm. Comparisons were made using the Student's t-test between gel images of the diabetes and control groups. The differentially expressed protein spots $(\mathrm{P}<0.05)$ with 2 -fold or more increased or decreased intensity between the two groups were selected and subjected to further identification by LC-ESI-MS/MS analysis. Briefly proteins selected were excised from the gels, washed, dehydrated and digested with $12.5 \mathrm{ng} / \mathrm{ml}$ trypsin in $0.1 \mathrm{M}$ $\mathrm{NH}_{4} \mathrm{HCO}_{3}$. LC-ESI-MS/MS analysis was performed using a Finnigan LTQ mass spectrometer (ThermoQuest, San Jose, CA) coupled with a Surveyor HPLC system (ThermoQuest). Protein identification based on the raw MS/MS data was performed using the SEQUEST software (Thermo Finnigan) by searching against the Swiss-Prot rat protein database. The identification results were filtered based on the XCorr $(1+$, $\geq 1.9 ; 2+, \geq 2.2 ; 3+, \geq 3.75)$ and the $\Delta \mathrm{Cn}(\geq 0.1)$.

Bioinformatics analysis. Various online databases containing experimental information of protein interactions and associations have been set up with the development of high throughput proteomics technology (17). Bioinformatics analysis of the protein-protein interaction (PPI) was carried out using PPI Spider (18), which is a freely available web-based tool for the interpretation of experimentally derived proteins in the context of a global PPI network. A dataset containing the standard gene symbols of the identified proteins was uploaded and a PPI network was mapped with the default parameter settings. 
A
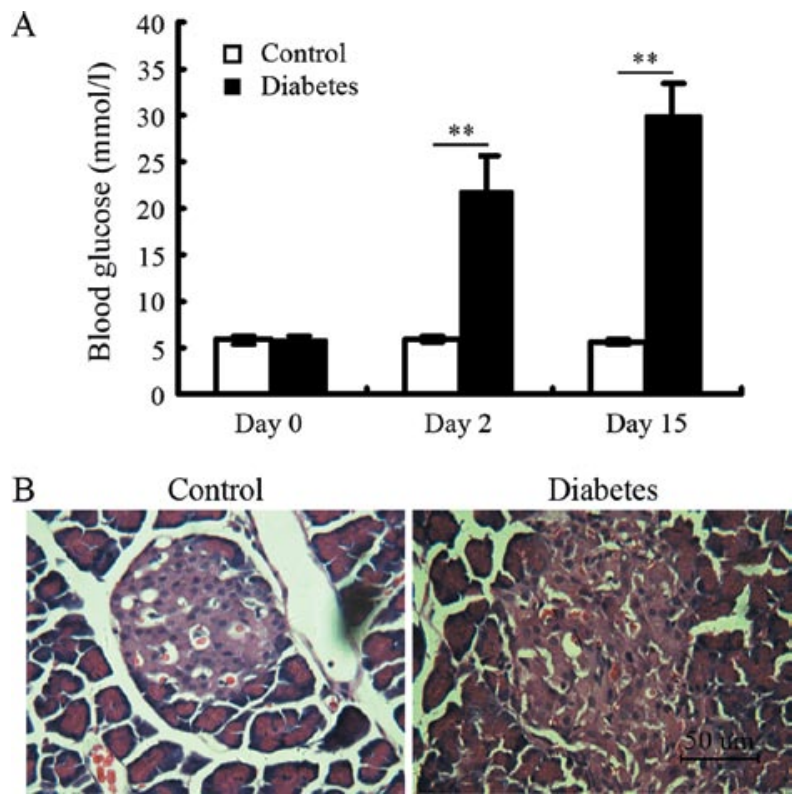

Figure 1. A rat model of T1DM was successfully induced by streptozotocin (STZ) treatment. Effects of STZ on blood glucose (A). Blood glucose was measured by the Accu-Chek Advantage glucometer. Blood glucose was significantly elevated in the diabetes group. Data are expressed as the means $\pm \mathrm{SD}, \mathrm{n}=8 .{ }^{* *} \mathrm{P}<0.01$, diabetes group vs. control group (Student's $\mathrm{t}$-test). STZ caused damage to pancreatic islets (B). The sections were stained with haematoxylin and eosin. Pancreatic islets shown are representatives of each group. Scale bar, $50 \mu \mathrm{m}$.
Western blotting. Three independent experiments were carried out for Western blot analysis. An aliquot (containing $40 \mu \mathrm{g}$ protein) of the pancreas sample was denatured by mixing with an equal volume of $2 \mathrm{X}$ sample loading buffer and then boiling at $99.5^{\circ} \mathrm{C}$ for $5 \mathrm{~min}$. Proteins were separated by a $14 \%$ SDS-PAGE gel and electroblotted onto a $0.45 \mu \mathrm{m}$ PVDF membrane (BioRad). After the PVDF membrane was blocked in $10 \mathrm{mM}$ PBS with $0.1 \%$ Tween-20 and 5\% dehydrated skim milk, the membrane was incubated with primary antibodies overnight at $4^{\circ} \mathrm{C}$. The primary antibodies used were the goat anti-carbonyl reductase 1 (Cbr1) polyclonal antibody (1:2,000; Santa Cruz Biotechnology, Santa Cruz, CA), and the horseradish peroxidaseconjugated anti-rat $\beta$-actin monoclonal antibody $(1: 8,000$; Kangcheng, Shanghai, China). Blots were then incubated with the horseradish peroxidase-conjugated rabbit anti-goat IgG (Santa Cruz Biotechnology) for $1 \mathrm{~h}$ at room temperature at a 1:10,000 dilution and then visualized using chemiluminescence (ECL Plus; Amersham Pharmacia Biotech, Piscataway, NJ, USA). The blots were scanned by a Doc XR System (Bio-Rad) and analyzed using the Quantity One software (Version 4.6; Bio-Rad).

Statistical analysis. Significant differences between the diabetes and control groups were determined by the Student's t-test. The statistical analysis for the PPI Spider was performed using the Monte Carlo simulation procedure. Data are expressed as
A
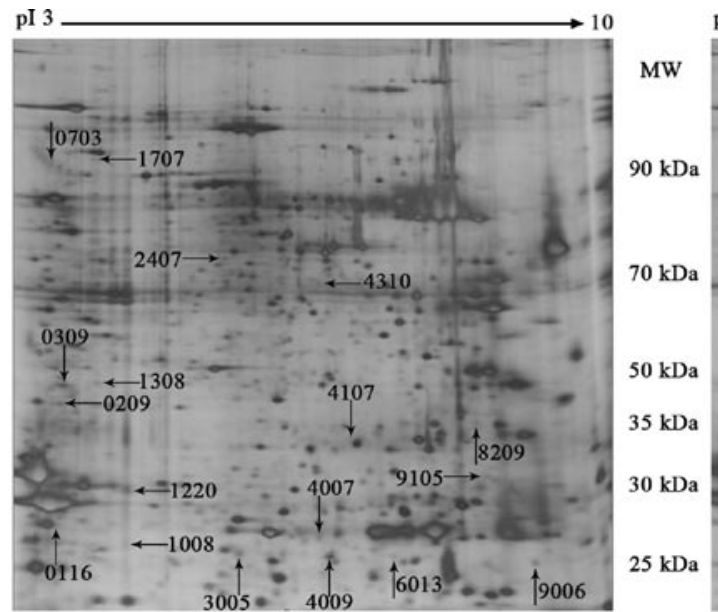

B

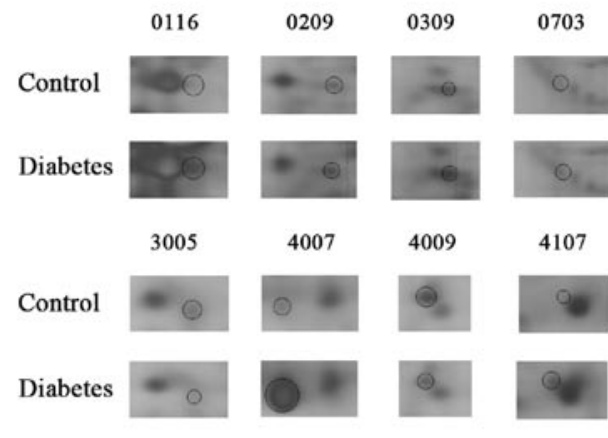

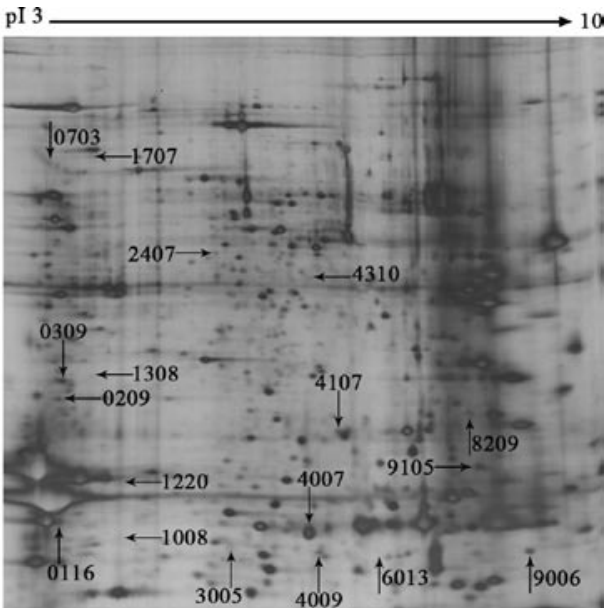
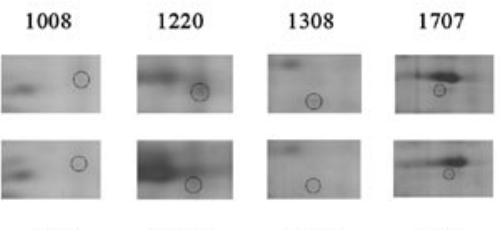

2407
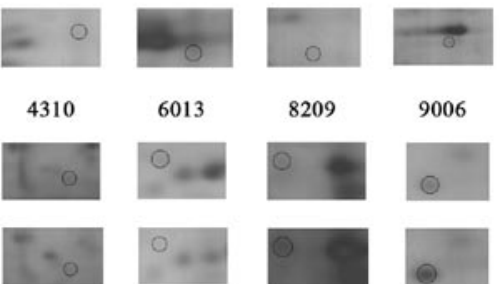

9006
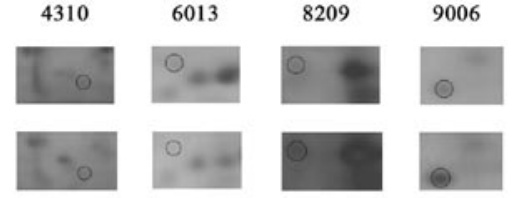
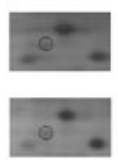

9105

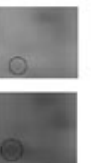

Figure 2. Representative 2-DE gel maps of the pancreas isolated from control rats (left) and diabetic rats (right). (A) Total protein extracts were separated on 17-cm nonlinear IPG strips (pH 3-10) in the first dimension followed by 13\% SDS-PAGE in the second dimension and visualized by silver staining. (B) Cropped images of the 18 differentially $(\mathrm{P}<0.05)$ expressed protein spots with a 2 -fold or more increased or decreased intensity between the diabetic and control groups. The numbers correspond to the spot identification numbers listed in Table I. The protein spots were symmetrically circled in the two groups. The ppm volumes of these protein spots are listed in Table I. 
Table I. 2-DE analysis of differentially expressed proteins of the pancreas of diabetic rats induced by STZ.

\begin{tabular}{|c|c|c|c|c|}
\hline \multirow[b]{2}{*}{ Spot } & \multicolumn{2}{|c|}{ Spot volume (ppm) } & \multirow[b]{2}{*}{ Fold-change } & \multirow[b]{2}{*}{ P-value } \\
\hline & $\begin{array}{c}\text { Control } \\
(\text { mean } \pm \mathrm{SD})\end{array}$ & $\begin{array}{c}\text { Diabetes } \\
(\text { mean } \pm S D)\end{array}$ & & \\
\hline 0116 & $1087.8 \pm 284.5$ & $2408.8 \pm 740.8$ & 2.21 & $<0.05$ \\
\hline 0209 & $816.6 \pm 309.2$ & $2719.3 \pm 958.5$ & 3.33 & $<0.05$ \\
\hline 0309 & $1938.5 \pm 709.5$ & $5357.4 \pm 1930.7$ & 2.76 & $<0.05$ \\
\hline 0703 & $475.1 \pm 260.1$ & $1441.5 \pm 462.2$ & 3.03 & $<0.05$ \\
\hline 1008 & $472.1 \pm 86.7$ & $181.1 \pm 35.7$ & 0.38 & $<0.05$ \\
\hline 1220 & $3220.9 \pm 1390.9$ & $572.0 \pm 456.2$ & 0.18 & $<0.05$ \\
\hline 1308 & $677.3 \pm 192.3$ & $283.7 \pm 110.0$ & 0.42 & $<0.05$ \\
\hline 1707 & $305.1 \pm 99.2$ & $648.2 \pm 125.8$ & 2.12 & $<0.05$ \\
\hline 2407 & $452.8 \pm 25.3$ & $1060.4 \pm 289.4$ & 2.34 & $<0.05$ \\
\hline 3005 & $1837.1 \pm 174.6$ & $553.3 \pm 101.2$ & 0.30 & $<0.05$ \\
\hline 4007 & $1470.4 \pm 309.6$ & $4250.0 \pm 757.1$ & 2.89 & $<0.05$ \\
\hline 4009 & $4096.8 \pm 1345.5$ & $1737.5 \pm 507.9$ & 0.42 & $<0.05$ \\
\hline 4107 & $511.4 \pm 96.3$ & $2220.4 \pm 813.9$ & 4.34 & $<0.05$ \\
\hline 4310 & $893.0 \pm 221.1$ & $249.4 \pm 59.2$ & 0.28 & $<0.05$ \\
\hline 6013 & $429.0 \pm 53.8$ & $197.2 \pm 32.1$ & 0.46 & $<0.05$ \\
\hline 8209 & $729.7 \pm 222.6$ & $1469.1 \pm 383.3$ & 2.01 & $<0.05$ \\
\hline 9006 & $1029.0 \pm 224.5$ & $2667.0 \pm 446.0$ & 2.59 & $<0.05$ \\
\hline 9105 & $1253.2 \pm 574.3$ & $3765.5 \pm 1106.3$ & 3.00 & $<0.05$ \\
\hline
\end{tabular}

2-DE of all samples was performed in triplicate.

the mean $\pm \mathrm{SD}$. A P-value $<0.05$ was considered statistically significant.

\section{Results}

Rat model for TIDM evaluated by blood glucose levels and histology study of pancreatic islets. After STZ injection, blood glucose levels in the diabetes group were significantly increased compared to those in the control group. Blood glucose levels rose to $21.73 \pm 3.9 \mathrm{mmol} / 1$ on Day 2 (Fig. 1A), indicating that diabetes was successfully induced by STZ. Furthermore, blood glucose in the diabetes group was further elevated by Day 15. Histological analysis of pancreatic islets using haematoxylin and eosin staining, demonstrated that STZ caused serious damage to the pancreatic islets in the diabetes group. In specific, islet deformation, irregular distribution of cells, and cell atrophy with karyopyknosis and karyorrhexis were observed (Fig. 1B).

Differentially expressed protein spots separated by 2-DE. Representative two-dimensional gel images of pancreas of the control and diabetes groups are shown in Fig. 2A. Each gel resolved up to 2,000 protein spots. The proteome maps of pancreas in the diabetes and control groups were compared with the PDQuest software to identify protein spot variations. Differentially expressed protein spots $(\mathrm{P}<0.05)$ with 2 -fold or more increased or decreased intensity were scored. Eleven protein spots were up-regulated and 7 protein spots were down-regulated in the diabetes group as marked with arrows in Fig. 2A and highlighted by the expanded plots in Fig. 2B. The average intensity values and the standard deviations of the spots, the statistical assay results, and the -fold differences between the diabetes and control groups are listed in Table I. The fold-difference is represented by the ratio of the intensity value of the diabetes group to that of the control group.

Identification of differentially expressed proteins by LC-ESI-MS/ $M S$. After analyzing the 2-DE gels, peptides were extracted from each differentially expressed protein spot by in-gel trypsin digestion, and proteins were identified using LC-ESI-MS/MS. The results of the LC-ESI-MS/MS analysis are summarized in Table II, such as gene symbol, Swiss-Prot accession no., theoretical $\mathrm{MW} / \mathrm{pI}$, unique peptides and sequence coverage. The results of the LC-ESI-MS/MS analysis of spot 4009 as a representative example are shown in Figs. 3 and 4.

Protein interaction network by bioinformatics analysis. The PPI network created by PPI Spider covered 10 identified proteins (Fig. 5). Notably, 10 proteins were connected by the intermediate protein, GLUT4 [solute carrier family 2 (facilitated glucose transporter), member 4], which promotes the transport of glucose from the blood to target tissues (19).

Validation of Cbrl by Western blotting. Western blotting was used to validate the expression change of Cbrl between the diabetes and control groups. Consistent with the proteomics 


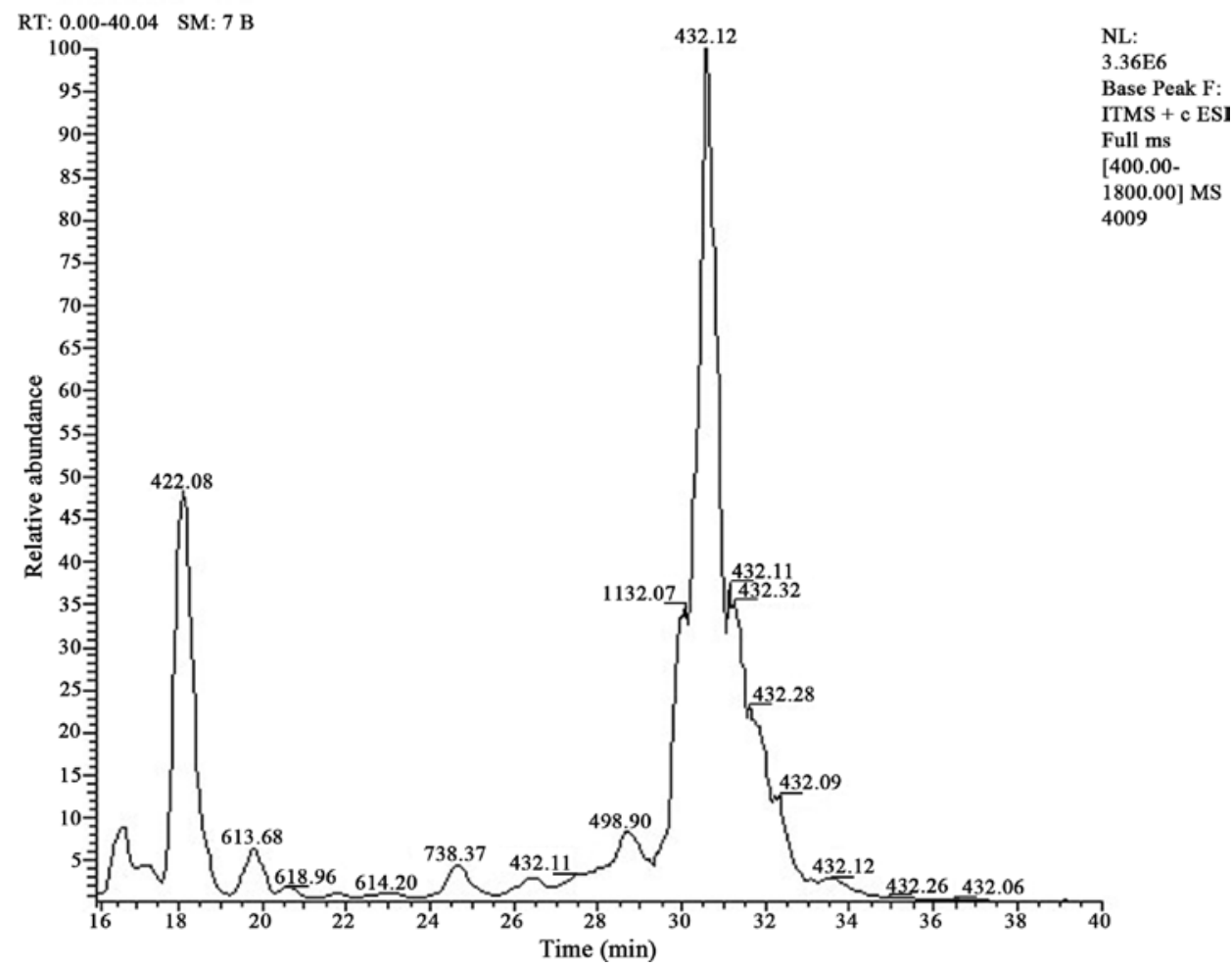

Figure 3. LC-MS analysis of trypsin digests from spot 4009. Base peak chromatogram showing the peptide peaks.

A 4009 \# 3687 RT: 20.85 NL: 3.82E2

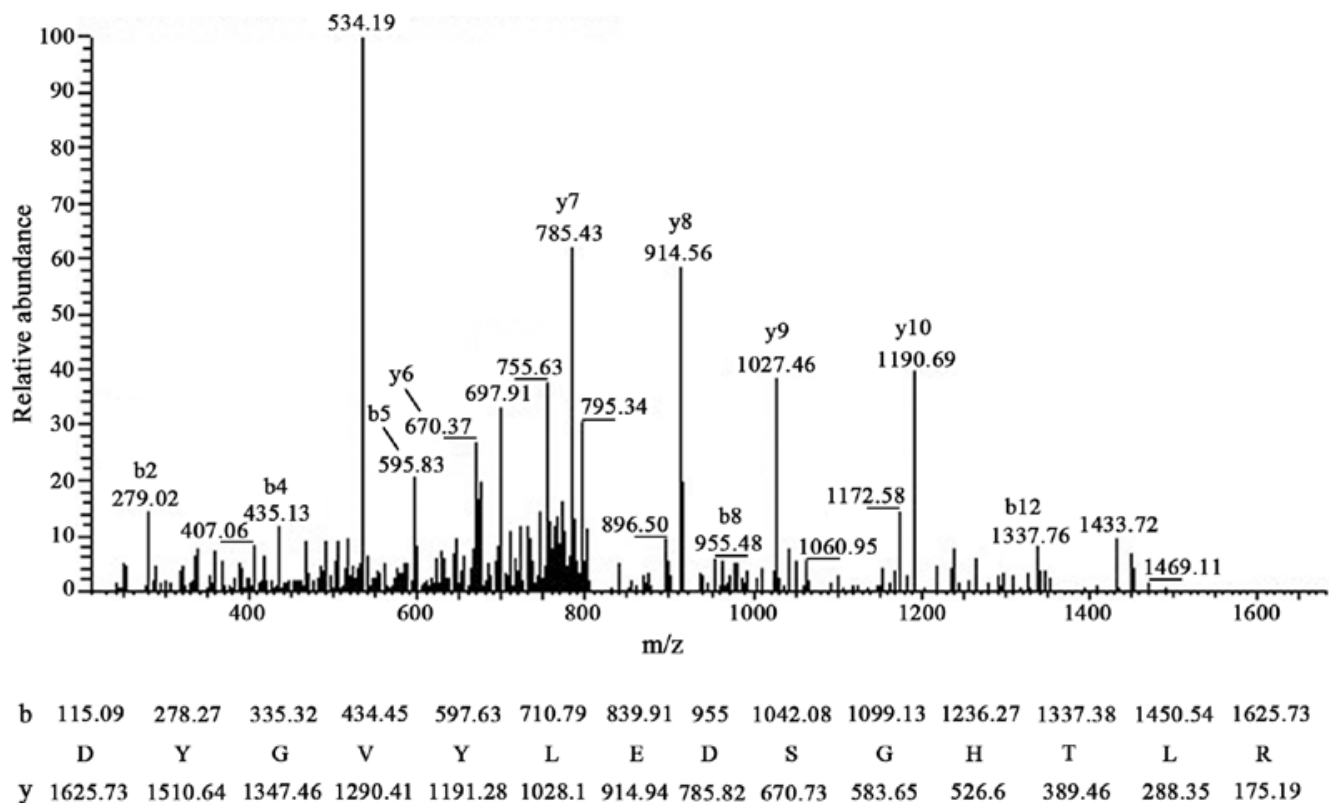

Figure 4. MS/MS analysis of spot 4009. (A) MS/MS spectrum of the double charge precursor ion at retention time 20.85 min in the base peak chromatogram of spot 4009 as shown in Fig. 3. (B) A sequence was confirmed from the labeled b- and y-ions in the spectrum. Fragments observed in the spectrum are assigned.

results, Cbrl was also found to be up-regulated in the diabetes group (Fig. 6).

\section{Discussion}

The rat model of STZ-induced T1DM is commonly employed in the field of diabetes research (8). In the present study, this rat model of T1DM was successfully established as demon- strated by the observed hyperglycemia and damage of the pancreatic islets. Using 2-DE/LC-ESI-MS/MS proteomic analysis, we compared the proteome maps of the pancreas of STZ-induced diabetic rats with those of the normal controls, and identified 18 differentially expressed protein spots.

We found that a consequence of STZ-induced stress is the increased activity of $60 \mathrm{kDa}$ heat shock protein (HSP60). HSPs belong to chaperones which can protect the cell from 
Table II. Results of protein identifications of differentially expressed proteins using LC-ESI-MS/MS.

\begin{tabular}{|c|c|c|c|c|c|c|}
\hline Spot & Protein name & Gene symbol & $\begin{array}{l}\text { Swiss-Prot/RefSeq/ } \\
\text { TrEMBL accession no. }\end{array}$ & $\begin{array}{l}\text { Theoretical } \\
\mathrm{MW}(\mathrm{kDa}) / \mathrm{pI}\end{array}$ & $\begin{array}{l}\text { Matched/ unique } \\
\text { peptides }\end{array}$ & $\begin{array}{c}\text { Sequence } \\
\text { coverage }(\%)\end{array}$ \\
\hline 0116 & Anionic trypsin-1 & Prss1 & P00762 & $26.0 / 4.71$ & $3 / 1$ & 8.13 \\
\hline 0209 & Elongation factor $1-\delta$ & Eef1d & Q9WUN0 & $28.8 / 4.86$ & $7 / 3$ & 14.79 \\
\hline 0309 & Elongation factor $1-\delta$ & Eef1d & Q9WUN0 & $28.8 / 4.86$ & $11 / 4$ & 19.46 \\
\hline 0703 & Tubulin $\alpha-1 \mathrm{~A}$ chain & Tuba1a & P68370 & $50.1 / 4.94$ & $6 / 6$ & 19.51 \\
\hline 1008 & $\begin{array}{l}\text { Isoform } 1 \text { of tubulin } \\
\beta-5 \text { chain }\end{array}$ & Tubb5 & P69897-1 & $49.7 / 4.78$ & $7 / 4$ & 15.54 \\
\hline 1220 & Junction plakoglobin & Jup & Q6P0K8 & $81.8 / 5.75$ & $10 / 6$ & 10.34 \\
\hline 1308 & Tubulin $\alpha-1 \mathrm{~A}$ chain & Tuba1a & P68370 & $50.1 / 4.94$ & $2 / 2$ & 7.54 \\
\hline 1707 & $\begin{array}{l}\text { Transitional endoplasmic } \\
\text { reticulum ATPase }\end{array}$ & Vcp & P46462 & $89.5 / 5.14$ & $6 / 4$ & 7.30 \\
\hline 2407 & $\begin{array}{l}26 \text { S protease regulatory } \\
\text { subunit } 7\end{array}$ & Psmc2 & Q63347 & $48.6 / 5.59$ & $3 / 2$ & 6.93 \\
\hline 3005 & Anionic trypsin-1 & Prss1 & P00762 & $30.0 / 4.71$ & $9 / 1$ & 8.13 \\
\hline 4007 & Trypsin-4 & LOC286960 & P12788 & $26.6 / 6.38$ & $23 / 8$ & 51.01 \\
\hline 4009 & Peroxiredoxin 4 & $\operatorname{Prdx} 4$ & NP_445964 & $31.0 / 6.18$ & $2 / 2$ & 8.79 \\
\hline 4107 & $\begin{array}{l}\Delta^{3,5}-\Delta^{2,4} \text {-dienoyl- } \\
\text { CoA isomerase }\end{array}$ & Ech1 & Q62651 & $36.2 / 8.14$ & $5 / 4$ & 15.60 \\
\hline 4310 & $\begin{array}{l}78 \mathrm{kDa} \text { glucose-regulated } \\
\text { protein }\end{array}$ & Hspa5 & P06761 & $72.3 / 5.07$ & $7 / 4$ & 8.56 \\
\hline 6013 & $\begin{array}{l}\text { Isoform } 1 \text { of tubulin } \\
\beta-5 \text { chain }\end{array}$ & Tubb5 & P69897-1 & $49.7 / 4.78$ & $5 / 4$ & 12.39 \\
\hline 8209 & $\begin{array}{l}\text { Hydroxyacyl-coenzyme A } \\
\text { dehydrogenase }\end{array}$ & Hadhsc & Q9WVK7 & $34.4 / 8.83$ & $3 / 2$ & 6.05 \\
\hline 9006 & $60 \mathrm{kDa}$ heat shock protein & Hspd1 & P63039 & $61.0 / 5.91$ & $5 / 4$ & 9.77 \\
\hline 9105 & $\begin{array}{l}\text { Carbonyl reductase } \\
\text { (NADPH) } 1\end{array}$ & Cbr1 & P47727 & $30.6 / 8.21$ & $22 / 10$ & 39.71 \\
\hline
\end{tabular}

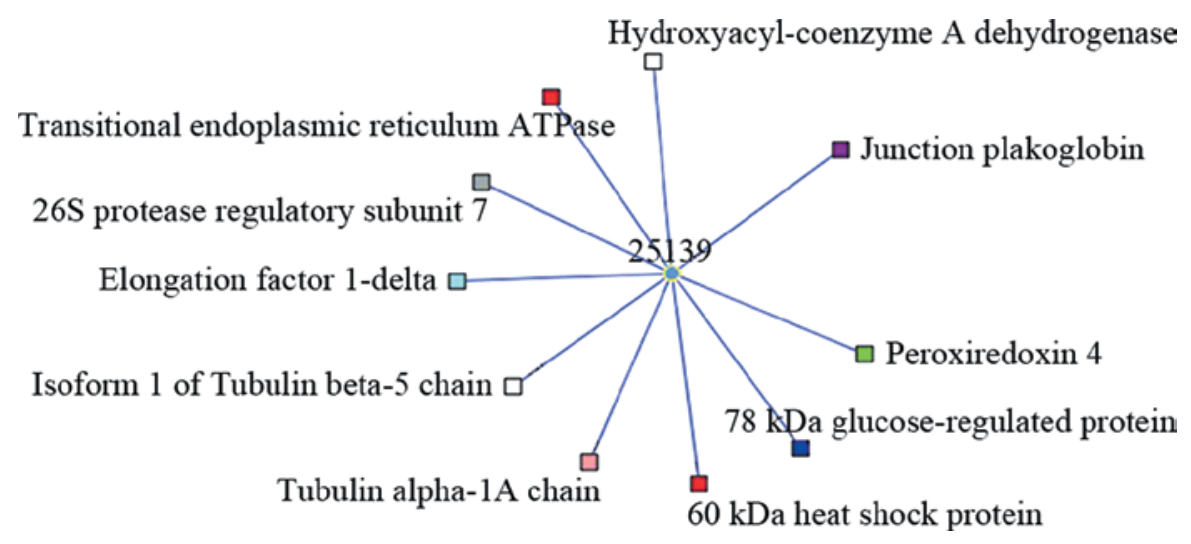

Figure 5. The in silico network inferred by PPI Spider. The proteins identified in the proteomic study are marked by squares. The PPI Spider network model covers 10 identified proteins. The intermediate protein not detected in the proteomic study is marked by a circle and by its corresponding Entrez gene ID: 25139 repesenting GLUT4 [solute carrier family 2 (facilitated glucose transporter), member 4].

harmful conditions, such as oxidative stress, extreme temperature changes and toxic drugs (20). Nevertheless, it was also reported that HSP60 may play a role in the onset of T1DM. NOD mice develop insulitis and diabetes through a process involving autoimmunity to HSP60 (21), and the increased HSP60 in fibroblasts may be pathophysiologically related to the development of nephropathy in T1DM (22). Whether the increased expression of HSP60 delays the onset of T1DM is intriguing. 
A
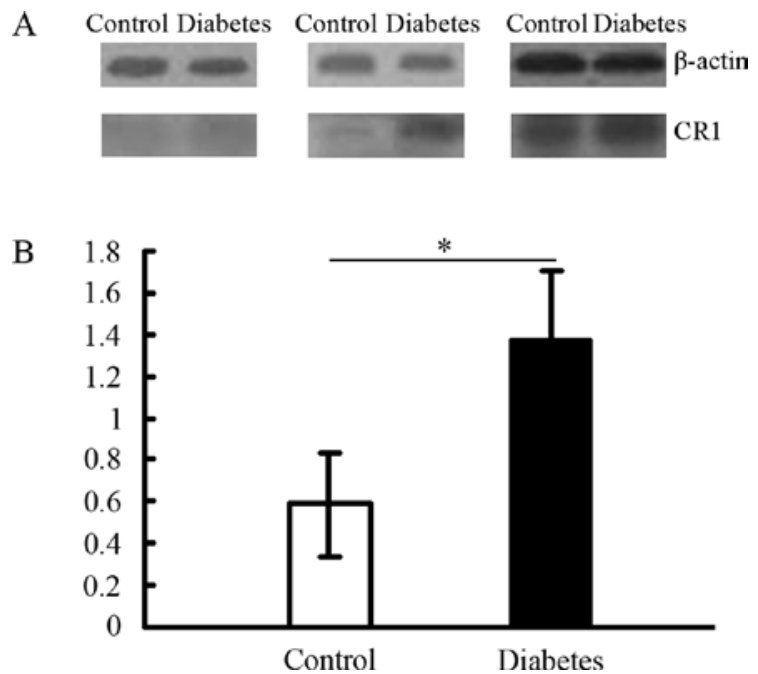

Figure 6. Validation of pancreatic Cbrl levels by Western blotting. (A) Three independent Western blots of Cbr1. $\beta$-actin was used to control equal loading. (B) The densitometric quantification of Cbrl is expressed as the fold-change compared to $\beta$-actin. The data are expressed as the mean \pm SD. Statistical analysis was performed using the Student's test. ${ }^{*} \mathrm{P}<0.05$, for the diabetes group compared to the control group. The expression pattern of Cbrl by Western blotting was in agreement with that of 2-DE.

GRP78 is an endoplasmic reticulum chaperone whose expression is increased upon endoplasmic reticulum stress (23). In our study, GRP78 expression was suppressed in the pancreas of diabetic rats. It was reported that treatment of cultured rat $\mathrm{FaO}$ liver cells with high levels of glucose resulted in reduced GRP78 expression (24).

The increased oxidative stress in the STZ-induced diabetic model was also reflected in our study by the up-regulation of Cbrl and the down-regulation of peroxiredoxin 4 (PRX4). Cbrl has received much attention, since it is related to diabetic complications, representing a significant pathway for the detoxification of reactive aldehydes derived from lipid peroxidation $(25,26)$. Both proteomics and Western blotting demonstrated that Cbrl was significantly increased in the pancreas of diabetic rats, suggest the increased lipid peroxidation in STZ-induced T1DM. Peroxiredoxins are a family of newly discovered enzymes with an antioxidative function, consisting of six members in mammals (27-29). Bast et al (30) reported that PRX1 and PRX2 were up-regulated in the cultured insulinoma cells exposed to various stress agents, including the diabetogenic substances, alloxan and STZ. However, in our study, we found that PRX4 was down-regulated (over 2 -fold) in the pancreas of diabetic rats, which may result in less capacity to attenuate oxidative damage and contribute to the progressive deterioration of $\beta$ cells.

The Wnt pathway is one of the central pathways that control organismal growth and differentiation (31), and is critical in pancreatic development (32). It also plays a very profound role in glucose and lipid metabolism (33). In the present study, we found that plakoglobin, also known as $\gamma$-catenin (34) which was reported to play a unique role in the Wnt pathway $(35,36)$, was down-regulated in the pancreas of diabetic rats. It has also been reported that oxidative stress can antagonize the Wnt pathway (33), while this pathway can inhibit apoptosis during oxidative stress (37). In mice, the Wnt pathway is necessary for the proliferation of islet $\beta$ cells (38), leading to $\beta$ cell expansion, increased insulin production, and enhanced glucose handling. Thus, oxidative stress and the Wnt pathway may be closely related to T1DM, as supported by our proteomic results.

In the absence of insulin, there is an increase in fat breakdown and fatty acid oxidation (1). Hydroxyacyl-CoA dehydrogenase $(\mathrm{HCDH})$ participates in the degradation of straight-chain saturated fatty acids, and $\Delta^{3,5}, \Delta^{2,4}$-dienoyl-CoA isomerase is implicated in the degradation of fatty acids with double bonds $(39,40)$. The up-regulation of these two enzymes indicates an involvement of increased fatty acid degradation of the pancreas in STZ-induced T1MD. A large body of research has demonstrated that enhanced delivery of fatty acids to non-adipose tissues can lead to both impaired glucose-stimulated insulin secretion and insulin resistance (41). Elongation factor 1 plays a role in protein synthesis. It was up-regulated in the pancreas of diabetic rats. The $26 \mathrm{~S}$ protease regulatory subunit 7 was also increased. It has previously been reported that the proteasome complex (26S) plays a role in the IL-1 $\beta$-induced inhibition of $\beta$-cell function (42). Energy transduction abnormality was also found as manifested by the up-regulation of transitional endoplasmic reticulum (TER) ATPase. A previous study showed that TER ATPase was increased in rat islets of Langerhans treated with interleukin-1 $\beta$ (13).

A functional analysis of protein-protein interactions revealed that most of these differentially expressed proteins were associated with the protein GLUT4. Considering that GLUT4 is closely related to type 2 diabetes (43) and since STZ is selectively accumulated in pancreatic $\beta$ cells via GLUT2 $(44,45)$, and insulin-producing cells that do not express this glucose transporter are resistant to STZ $(46,47)$, it may be that in the present study GLUT2 affected the biological process of glucose transport. Studies also showed that GLUT2 protein and mRNA expression was decreased in the pancreatic islets isolated from MLD-STZ-treated mice $(47,48)$, which may contribute to the protection of islet cells from an excessive influx of glucose, and consequently a reduced intracellular protein glycation and free radical generation.

In summary, based on 2-DE/LC-ESI-MS/MS techniques, we identified 18 differentially expressed proteins in the pancreas of diabetic rats induced by STZ. HSP60, Cbr1, HCDH, $\Delta^{3,5}, \Delta^{2,4}$-dienoyl-CoA isomerase, elongation factor $1-\delta, 26 \mathrm{~S}$ protease regulatory subunit 7, TER ATPase were up-regulated, while GRP78, PRX4 and plakoglobin were down-regulated. These results and the bioinformatics analysis suggest that oxidative stress, the Wnt pathway, fatty acid degradation and glucose transport may be closely related to T1DM. Our study provides potential biomarkers for T1DM and new clues for future diabetes research.

\section{Acknowledgements}

This study was supported by the National Natural Science Foundation of China (nos. 30873299, 90409014, 30701123), and by the Shanghai Leading Academic Discipline Project (S30304).

\section{References}

1. Kelly MA, Rayner ML, Mijovic CH and Barnett AH: Molecular aspects of type 1 diabetes. Mol Pathol 56: 1-10, 2003. 
2. Rösen P, Nawroth PP, King G, Möller W, Tritschler HJ and Packer L: The role of oxidative stress in the onset and progression of diabetes and its complications: a summary of a Congress Series sponsored by UNESCO-MCBN, the American Diabetes Association and the German Diabetes Society. Diabetes Metab Res Rev 17: 189-212, 2001.

3. Maritim AC, Sanders RA and Watkins JB III: Diabetes, oxidative stress, and antioxidants: a review. J Biochem Mol Toxicol 17: 24-38, 2003.

4. Lenzen S, Drinkgern J and Tiedge M: Low antioxidant enzyme gene expression in pancreatic islets compared with various other mouse tissues. Free Radic Biol Med 20: 463-466, 1996.

5. Karlsen AE, Sparre T, Nielsen K, Nerup J and Pociot F: Proteome analysis--a novel approach to understand the pathogenesis of Type 1 diabetes mellitus. Dis Markers 17: 205-216, 2001.

6. Resjö S, Berger K, Fex M and Hansson O: Proteomic studies in animal models of diabetes. Proteomics Clin Appl 2: 654-669, 2008.

7. Karabatas LM, Pastorale C, de Bruno LF, et al: Early manifestations in multiple-low-dose streptozotocin-induced diabetes in mice. Pancreas 30: 318-324, 2005.

8. Wu KK and Huan Y: Streptozotocin-induced diabetic models in mice and rats. Curr Protoc Pharmacol 40: 1-14, 2008.

9. Kolb H: Mouse models of insulin dependent diabetes: low-dose streptozocin-induced diabetes and nonobese diabetic (NOD) mice. Diabetes Metab Rev 3: 751-778, 1987.

10. Sanchez JC, Chiappe D, Converset V, et al: The mouse SWISS-2D PAGE database: a tool for proteomics study of diabetes and obesity. Proteomics 1: 136-163, 2001.

11. Xie X, Li S, Liu S, Lu Y, Shen P and Ji J: Proteomic analysis of mouse islets after multiple low-dose streptozotocin injection. Biochim Biophys Acta 1784: 276-284, 2008.

12. Andersen HU, Fey SJ, Larsen PM, et al: Interleukin-1beta induced changes in the protein expression of rat islets: a computerized database. Electrophoresis 18: 2091-2103, 1997.

13. Larsen PM, Fey SJ, Larsen MR, et al: Proteome analysis of interleukin-1beta-induced changes in protein expression in rat islets of Langerhans. Diabetes 50: 1056-1063, 2001.

14. Christensen UB, Larsen PM, Fey SJ, et al: Islet protein expression changes during diabetes development in islet syngrafts in BB-DP rats and during rejection of BB-DP islet allografts. Autoimmunity 32: $1-15,2000$.

15. Sparre T, Christensen UB, Mose Larsen P, et al: IL-1beta induced protein changes in diabetes prone BB rat islets of Langerhans identified by proteome analysis. Diabetologia 45: 1550-1561, 2002.

16. Yang M, Liu W, Wang CY, et al: Proteomic analysis of differential protein expression in early process of pancreatic regeneration in pancreatectomized rats. Acta Pharmacol Sin 27: 568-578, 2006.

17. Chaurasia G, Iqbal Y, Hänig C, Herzel H, Wanker EE and Futschik ME: UniHI: an entry gate to the human protein interactome. Nucleic Acids Res 35: D590-D594, 2007.

18. Antonov AV, Dietmann S, Rodchenkov I and Mewes HW: PPI spider: a tool for the interpretation of proteomics data in the context of protein-protein interaction networks. Proteomics 9: 2740-2749, 2009.

19. Kandror KV: A long search for Glut4 activation. Sci STKE 2003 PE5, 2003.

20. Hartl FU: Molecular chaperones in cellular protein folding. Nature 381: 571-579, 1996.

21. Quintana FJ, Rotem A, Carmi P and Cohen IR: Vaccination with empty plasmid DNA or $\mathrm{CpG}$ oligonucleotide inhibits diabetes in non-obese diabetic mice: modulation of spontaneous $60-\mathrm{kDa}$ heat shock protein autoimmunity. J Immunol 165: 6148-6155, 2000.

22. Tessari P, Puricelli L, Iori E, et al: Altered chaperone and protein turnover regulators expression in cultured skin fibroblasts from type 1 diabetes mellitus with nephropathy. J Proteome Res 6 : 976-986, 2007.

23. Harding HP, Calfon M, Urano F, Novoa I and Ron D: Transcriptional and translational control in the Mammalian unfolded protein response. Annu Rev Cell Dev Biol 18: 575-599, 2002.

24. Shiu RP, Pouyssegur J and Pastan I: Glucose depletion accounts for the induction of two transformation-sensitive membrane proteins in Rous sarcoma virus-transformed chick embryo fibroblasts. Proc Natl Acad Sci USA 74: 3840-3844, 1977.

25. Maser E: Neuroprotective role for carbonyl reductase? Biochem Biophys Res Commun 340: 1019-1022, 2006.
26. Bergholdt R, Nerup J and Pociot F: Fine mapping of a region on chromosome 21q21.11-q22.3 showing linkage to type 1 diabetes. J Med Genet 42: 17-25, 2005.

27. Fujii $\mathbf{J}$ and Ikeda Y: Advances in our understanding of peroxiredoxin, a multifunctional, mammalian redox protein. Redox Rep 7: 123-130, 2002.

28. Hoffrogge R, Mikkat S, Scharf C, et al: 2-DE proteome analysis of a proliferating and differentiating human neuronal stem cell line (ReNcell VM). Proteomics 6: 1833-1847, 2006.

29. Maurer MH, Feldmann RE Jr, Fütterer CD, Butlin J and Kuschinsky W: Comprehensive proteome expression profiling of undifferentiated versus differentiated neural stem cells from adult rat hippocampus. Neurochem Res 29: 1129-1144, 2004.

30. Bast A, Wolf G, Oberbäumer I and Walther R: Oxidative and nitrosative stress induces peroxiredoxins in pancreatic beta cells Diabetologia 45: 867-876, 2002.

31. Chien AJ and Moon RT: WNTS and WNT receptors as therapeutic tools and targets in human disease processes. Front Biosci 12: 448-457, 2007

32. Papadopoulou S and Edlund H: Attenuated Wnt signaling perturbs pancreatic growth but not pancreatic function. Diabetes 54: 2844-2851, 2005.

33. Manolagas SC and Almeida M: Gone with the Wnts: beta-catenin T-cell factor, forkhead box $\mathrm{O}$, and oxidative stress in age-dependent diseases of bone, lipid, and glucose metabolism. Mol Endocrinol 21: 2605-2614, 2007

34. Ozawa M, Baribault H and Kemler R: The cytoplasmic domain of the cell adhesion molecule uvomorulin associates with three independent proteins structurally related in different species. EMBO J 8: 1711-1717, 1989.

35. Charpentier E, Lavker RM, Acquista E and Cowin P: Plakoglobin suppresses epithelial proliferation and hair growth in vivo. J Cell Biol 149: 503-520, 2000.

36. Zhurinsky J, Shtutman M and Ben-Ze'ev A: Differential mechanisms of LEF/TCF family-dependent transcriptional activation by beta-catenin and plakoglobin. Mol Cell Biol 20: 4238-4252, 2000.

37. Chong ZZ and Maiese K: Targeting WNT, protein kinase B, and mitochondrial membrane integrity to foster cellular survival in the nervous system. Histol Histopathol 19: 495-504, 2004

38. Rulifson IC, Karnik SK, Heiser PW, et al: Wnt signaling regulates pancreatic beta cell proliferation. Proc Natl Acad Sci USA 104: 6247-6252, 2007.

39. Kunau WH, Dommes V and Schulz H: beta-Oxidation of fatty acids in mitochondria, peroxisomes, and bacteria: a century of continued progress. Prog Lipid Res 34: 267-342, 1995.

40. Hiltunen JK and Qin Y: beta-Oxidation: strategies for the metabolism of a wide variety of acyl-CoA esters. Biochim Biophys Acta 1484: 117-128, 2000.

41. Carpentier AC: Postprandial fatty acid metabolism in the development of lipotoxicity and type 2 diabetes. Diabetes Metab 34: 97-107, 2008

42. Kwon G, Corbett JA, Hauser S, Hill JR, Turk J and McDaniel ML: Evidence for involvement of the proteasome complex (26S) and NFkappaB in IL-1beta-induced nitric oxide and prostaglandin production by rat islets and RINm5F cells. Diabetes 47: 583-591, 1998.

43. Kennedy JW, Hirshman MF, Gervino EV, et al: Acute exercise induces GLUT4 translocation in skeletal muscle of normal human subjects and subjects with type 2 diabetes. Diabetes 48: 1192-1197, 1999.

44. Tjälve H, Wilander E and Johansson EB: Distribution of labelled streptozotocin in mice: uptake and retention in pancreatic islets. J Endocrinol 69: 455-456, 1976.

45. Karunanayake EH, Baker JR, Christian RA, Hearse DJ and Mellows G: Autoradiographic study of the distribution and cellular uptake of (14C) - streptozotocin in the rat. Diabetologia 12: $123-128,1976$.

46. Elsner M, Guldbakke B, Tiedge M, Munday R and Lenzen S: Relative importance of transport and alkylation for pancreatic beta-cell toxicity of streptozotocin. Diabetologia 43: 1528-1533, 2000.

47. Schnedl WJ, Ferber S, Johnson JH and Newgard CB: STZ transport and cytotoxicity. Specific enhancement in GLUT2-expressing cells. Diabetes 43: 1326-1333, 1994.

48. Wang Z and Gleichmann H: GLUT2 in pancreatic islets: crucial target molecule in diabetes induced with multiple low-doses of streptozotocin in mice. Diabetes 47: 50-56, 1998. 